\title{
The Present Situation and Strategy Analysis of WeChat Marketing
}

\author{
Xingyue Yeweng ${ }^{1, a}$ and Ming Yan ${ }^{2, b}$ \\ ${ }^{1,2}$ School of Management, Wuhan University of Technology, Wuhan, China \\ a117233094@qq.com, ${ }^{\mathrm{b}} 470601935 @ q q . c o m$
}

\begin{abstract}
Keywords: WeChat marketing; Network marketing; Marketing strategy; Enterprise marketing; Consumer behavior
\end{abstract}

\begin{abstract}
With the rapid development of China's economy, due to changes in the market competition and consumption mode, the enterprise marketing demand more and more prominent, WeChat marketing as a new type of network marketing, it has also become a hot topic for current research. WeChat marketing is a new marketing method, some enterprises in order to obtain good marketing effect, through WeChat to promote their products and services. A lot of companies like WeChat marketing, because WeChat marketing with instant messaging, low marketing costs, precise positioning of the user and other advantages. But we can not ignored that WeChat marketing in the stage of rapid development, there are still some shortcomings, such as lack of standardized, lack of marketing innovation, user information disclosure, restricted the marketing effectiveness. Based on the domestic and foreign scholars, this paper summarizes the development status of WeChat marketing, and puts forward the feasible strategy of WeChat marketing from the perspective of consumer behavior, which can provide reference for the WeChat marketing activities.
\end{abstract}

\section{Introduction}

In recent years, the network infrastructure construction in China has access to broadband and narrowband from low speed to the rapid evolution of high-speed fiber-optic access upgrade, China's Internet users continued to gain popularity, the scale and the scale of mobile phone users is increasing year by year. Operators for strong investment $4 \mathrm{G}, \mathrm{WiFi}$ hotspot rising, the popularity of mobile terminals and the mobile Internet Ecosystem continues to improve, the rapid development of mobile Internet to the Chinese created a hitherto unknown condition. As of December 2015, China's mobile phone users reached 679 million, compared with the traditional network, mobile Internet both showing a trend of rapid development in the number of users or technical level, for the majority of mobile phone users has become a new choice of PC end outside.

Riding the wave of the development of mobile Internet, a number of outstanding mobile Internet applications have emerged, greatly enriched and facilitated the lives of users, WeChat is one of the most representative applications. In 2011, the Tencent Inc launched a multi platform instant messaging software: WeChat, via voice, text, pictures, video and other ways to meet the user's daily social needs, and application of all kinds of innovation launched WeChat features, such as the public platform, shake, sweep, greatly enriched the playability and WeChat ease of use. With years of development iterations, WeChat is not just a communications APP, it has become a social, commercial, service-oriented, open financial ecological platform. Today WeChat live more than 650 million users, users all over the world in more than and 200 countries and regions, has become the most active in the field of social users the highest number of applications. WeChat as a huge ecological platform, not only to attract a large number of individual users, but also for enterprises to create a huge potential marketing value, WeChat marketing has become a hot spot of research. How to better carry out the self marketing of WeChat, realize the value of marketing and provide better service for the target customers, it is worth further study and discussion.

\section{Literature Review}

Because WeChat is only about five years, mainly in the domestic market, so foreign scholars for 
the research of WeChat less, but has done more research on some similar to WeChat's social networking software, can provide a reference. Joe Licari think social software has a great advantage in the business, to achieve real-time communication with customers, shorten the distance between customers, saving information storage space and cost ${ }^{[1]}$. Berold Kelly believes that social software due to be able to contact with the phone address book to be able to quickly attract more users, and the user's activity is relatively high, with great commercial value ${ }^{[2]}$. Mehdi Dadkhah pointed out that many social networking applications, including WeChat, including the number of mobile phone online certification registration, once the information leaked, it is likely to affect the user's privacy security ${ }^{[3]}$.

Domestic scholars pay more attention to WeChat marketing, WeChat as a social software, not only to meet the user's social needs, while the formation of a business platform for enterprises to provide superior marketing channels. Lei Zheng analysis of the influence of factors on the adoption of WeChat users, through an empirical study concluded that WeChat's ease of use, the use of risk, trust and social norms and other reasons will affect whether the user is willing to accept WeChat, but also factors such as gender, age, level of education such as the impact of ${ }^{[4]}$. Pan Chen put the user adoption behavior is divided into five dimensions of research, found that the influence from the society, the use of WeChat users of WeChat's motivation and the degree of attention to their privacy is an important factor, and in previous studies of perception factors in the impact on the continued use of the little ${ }^{[5]}$. Qingyuan Lv pointed out that WeChat with a huge user base and the background of the huge data analysis and processing capabilities, the data generated by the marketing value of ${ }^{[6]}$. WeChat by virtue of its data resources and enterprises to cooperate, making advertising more accurate, to achieve good communication efficiency. Yan Zhang from the perspective of communication, micro selection removed this feature of the instant research, detailed analysis and timeliness in WeChat marketing through different marketing mode to realize the principle of real-time, and to realize the real-time path ${ }^{[7]}$. Hong Zhao from the perspective of the current development situation of WeChat, the situation after the description and analysis of the use of enterprise in the background, for the future development of WeChat outlook, companies want to predict the future, provide relevant reference suggestions for WeChat marketing ${ }^{[8]}$. Xu Chen believes that WeChat has a unique advantage as well as a small range of information dissemination characteristics of the crowd, a small range of information dissemination will become a new trend in the future ${ }^{[9]}$; Zhuojie Shi, Yongdong Fang shows that WeChat has to meet the preferences of the majority of users, similar to the direct communication between people, can be combined with marketing activities, anytime, anywhere on the spread of brand value ${ }^{[10]}$. Siqi Miu analyzed the advantage of WeChat, the number of users including the advantages of technology, capital advantage, price advantage, user experience advantage, and analyzes the disadvantages, including the way of profit is not clear, friends are online privacy and security can not be determined, there is a huge risk, the WeChat opportunity everywhere, including intelligent mobile phone Internet is in rapid development, by the young composed of the consumer groups continue to expand, the competition between the telecom industry, and the operators of the class are contradictory feeling formed between the instant messaging tools outside WeChat and WeChat's threats include ${ }^{[11]}$; Xia Wang elaborated a variety of WeChat marketing activities and the use of WeChat marketing techniques ${ }^{[12]}$; Xingdong Fang and other scholars have expounded the main transmission way WeChat is one of the direct communication, including communication, spread between WeChat friends friends and relevant information, scope and frequency of each mode of transmission of information conveyed by different, WeChat has spread, strong privacy and mass communication ability is limited the characteristics of the real name ${ }^{[13]}$.

\section{WeChat marketing development status}

Concept of WeChat. WeChat enterprise marketing is the enterprises relying on the WeChat platform, use a variety of WeChat, a series of marketing activities for the majority of users of WeChat, because WeChat marketing has instant message push, the marketing of low cost, accurate user location and other advantages, which favored by the majority of enterprises, it is a new mode 
of network marketing. In recent years, the gradual formation and increase of WeChat sticky user groups, increasing the number of WeChat WeChat marketing companies are providing a good opportunity for the development of marketing. Enterprises can promote their own brand on the WeChat platform to promote their products, to provide users with convenient and efficient service.

Because WeChat is the online application, without time and place restrictions, users can subscribe to the relevant information according to their own needs, the enterprise according to the requirements of the user to provide relevant information and promotion services, can achieve a more precise marketing, achieve good marketing results. Enterprises can open the interface through the public platform from WeChat client access to the enterprise's website, you can also be displayed directly in the relevant activities of WeChat push information, membership management, customized services, etc.. The enterprise can according to various functions such as WeChat platform: the public number, circle of friends, sweep, near the people, to develop a variety of marketing solutions to achieve better marketing ${ }^{[14]}$.

Characteristics of WeChat. (1) Instant messaging. WeChat as a instant communication software, the mobile phone can receive messages pushed to the first time the corresponding reminder, to ensure that users can read in the first time, and WeChat is to push information, can guarantee the user to send information to push $100 \%$.(2) Users more accurate. WeChat users can freely choose to focus on the micro signal of the enterprise, once the choice of attention, to show users to some extent recognized by the enterprise, and therefore more likely to become potential customers of enterprises, enterprises push the information more accurate and efficient.(3) Diversification of marketing model. eChat has a variety of marketing mode, the public platform, sweep, shake, circle of friends, enterprises can adopt different marketing mix according to their own characteristics and marketing stage. (4) Low marketing costs. WeChat free to open to the use of the enterprise, for the enterprise, the cost is mainly concentrated in the cost of content and account management costs, compared to advertising, marketing and other ways to push the lower cost, higher efficiency. (5) High interaction. Through the WeChat public platform, users can directly feedback to the enterprise through text, pictures, etc., and can directly purchase, payment, the formation of positive interaction between business users, with higher marketing value.

WeChat Marketing Development Status. (1) WeChat marketing has a strong potential for development. WeChat marketing development trend in recent years more and more strong, because WeChat has the advantages of low cost, high interactivity, accurate positioning and other advantages, by the majority of enterprises, enterprises WeChat marketing network marketing methods become among the most fiery. With the increase of mobile Internet users and WeChat update iteration, WeChat marketing will continue to enrich the marketing approach, to provide a better user experience, resulting in greater marketing value.(2) Lack of industry norms. The marketing of Chinese enterprises compared to western developed countries started late, many enterprise marketing laws and regulations are not perfect, and the WeChat marketing is not good supervision, resulting in information disclosure, there are many problems such as fraud, vulgar content, industry norms to be strengthened. (3)WeChat marketing has homogenization phenomenon. WeChat marketing is an important part of the content push, enterprise through articles, videos and other ways to push to the user to attract users. Some enterprises due to the strength of the lack of content management capabilities, so there are a lot of plagiarism, reproduced and other phenomena, marketing methods and content repeat monotonous, homogeneity serious.

\section{Strategy Analysis of WeChat Marketing}

AISAS Model of WeChat Marketing. In 1898, Lewis, an American advertising expert, put forward the AIDMA model of consumer behavior, and consumers will go through five stages from exposure to information to purchase: Attention-Interest-Desire-Memory-Action. With the development of the Internet, the channels for consumers to obtain information become diverse, the traditional era of consumer behavior model is also developed from the AIDMA model into a AISAS model: Attention-Interest-Search-Action-Share. The search function of the Internet and the sharing function of the media have changed the behavior model of the consumer, shortening the steps of the 
consumer from noticing to buying, and the consuming rhythm becomes faster and faster. According to the AISAS model, the enterprise can through online and offline in the WeChat marketing promotion activities and publicity attracted the attention of consumers, consumers receive public account for subscription by benefits and services, public accounts to provide services and information through consumer culture consumers for products of interest and corporate goodwill, causing consumers to buy online and offline buy action, and to provide consumers with the purchase behavior after the share platform. as shown in Fig.1.

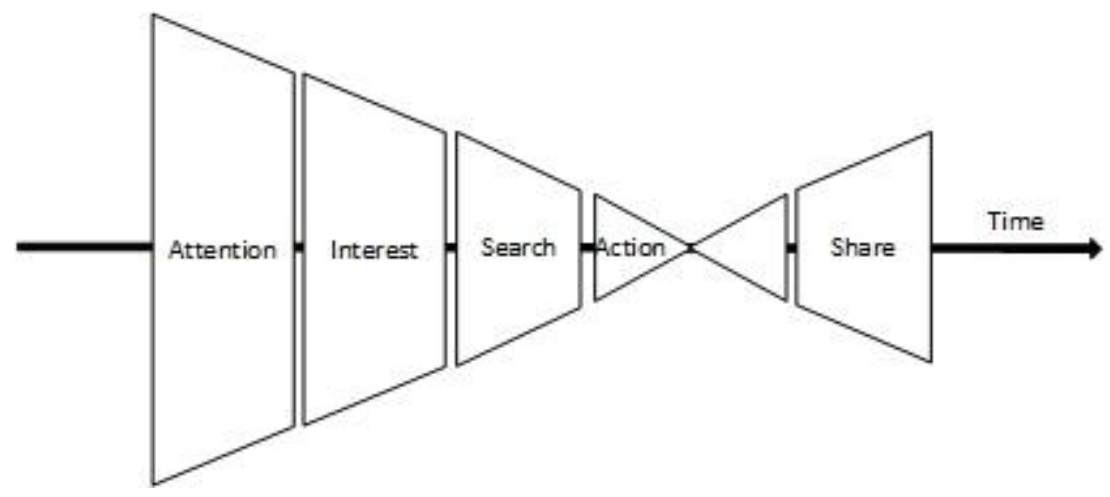

Figure 1. AISAS consumer behavior analysis model

WeChat Marketing Strategy. According to the AISAS model, WeChat marketing companies should focus on the following strategies: (1) Establishing a variety of marketing channels. Enterprises should make use of marketing activities to get the attention of consumers, through preferential activities or information interesting, practical access to the user's subscription. When consumers successfully become the enterprise public number of subscribers, to maintain the public number for the user to directly affect the attitude of consumers, in the premise of not interrupting consumers, push to consumers with accurate content demand, increase interaction with consumers, to provide convenient services for consumers will increase consumer interest for products and brands, and thus stimulate the buying interest. (2)Cultivateing user interest. WeChat is a feature of precision marketing, information transmission speed, fast proliferation. At present, many enterprises only take WeChat as an advertising platform, positioning is not clear, ignoring the content of construction, resulting in the loss of fans is very serious, therefore the determination of corporate positioning, in-depth study of the management focus on the user, according to the characteristics of precision marketing, cultivate consumer interest. (4)Ensure the smooth flow of online shopping channel. The development of network consumption channels has been very mature, to ensure the smooth flow of online shopping channels, is an important part of the enterprise will be transformed into consumers. Enterprises also need to pay attention to the construction of Jingdong, Taobao and other online shop, while doing a good job WeChat payment function, and note to strengthen network security management, and ultimately allow consumers to be satisfied. (5) Establishing sharing mechanism. The enterprise should establish the incentive mechanism of share value, consumers pay attention to articles of interest or consumption, can be sent through the circle of friends and friends to share, and achieved some practical benefits, in order to expand the scope of publicity and marketing, to further expand the enterprise marketing influence.

\section{Summary}

After continuous development and iteration, WeChat has more than just a communication social software, but also become a new way of life. WeChat brings together a large number of users through the convenience of the function, in the convenience of users, but also for the enterprise marketing has brought new opportunities. Due to the advantages of WeChat instant push, user precision, low marketing costs, attracting a large number of enterprises settled, hoping to expand the impact of WeChat marketing, to provide users with better service. However, due to the WeChat 
marketing related laws and regulations not perfect, marketing content homogeneity, user information security has been ignored and other reasons, resulting in some enterprises WeChat marketing is difficult to obtain the expected effect, serious loss of fans. Therefore, based on the AISAS model, when enterprise in the WeChat marketing process, and it should attract users through various marketing methods and high quality marketing content, and attach importance to the interaction with users, building and improving the online shopping platform, to provide consumers with convenient consumer services, and encourage users to share information, so as to achieve a better realization of the enterprise WeChat marketing results.

\section{References}

[1] Joe Licari. Best practices for instant messaging in business [J]. Network Security, 2005, 2005(5):4-7.

[2] Berold Kelly. Why Whats App is good for Facebook's business [J]. Finweek, 2014:36-37.

[3] Mehdi Dadkhah, Tole Sutikno, Shahaboddin Shamshirband. Social Network Applications and Free Online Mobile Numbers: Real Risk [J]. International Journal of Electrical and Computer Engineering, 2015, 5(2):175-176.

[4] Zheng Lei. Research on Influencing Factors of User Adoption in WeChat [D]. Beijing University of Posts and Telecommunications, 2013.

[5] Chen Pan. Research on WeChat User Adoption Based on Mobile Internet [D]. Huazhong University of Science and Technology, 2012.

[6] Lv Qingyuan. WeChat Marketing Value in the Era of Big Data [J]. Modern economic information, 2013, 20: 279.

[7] Zhang Yan. From the Perspective of Communication to Achieve Real-time Marketing Mode and Strategy_ A Case Study of WeChat Marketing [J]. China Publishing Journal,2013, 16:18-20.

[8] Zhao Hong. Research on the Development of WeChat Marketing [D]. Industrial and Commercial University of Chongqing, 2014.

[9] Chen Xu. WeChat Hot and Narrow Communication [J]. Youth Journalist, 2013(35):76-77.

[10] Shi Zhuojie, Fang Yongdong, On the Role of WeChat in Today's Marketing [J]. Chinese E-Commerce 2013(12):11.

[11] Miao Siqi. Development of WeChat in Mobile Internet Era Based on SWOT Model [J]. Consumer Electronics, 2013(10):82.

[12] Wang Xia, New Marketing Mode and Strategy Based on WeChat [J]. Management Observation, 2013(22):100-101.

[13]Fang Xingdong, Shi Xiansheng, Zhang Xiaorong, Zhang Jing. Research on the Communication Mechanism and Governance of WeChat [J]. Modern Communication, 2013, 35(6):122-127.

[14] Yan Jing. Research on the Influence Factors of User Stickiness of WeChat Marketing [D]. Jilin University, 2016. 